BMJ Paediatrics Open

\title{
Excretion of SARS-CoV-2 in breast milk: a single-centre observational study
}

\author{
Arun Prasad (D) , ${ }^{1}$ Yankappa N, ${ }^{1}$ Pradeep Kumar, ${ }^{1}$ Bhavesh Kant Chaudhary, \\ Binod Kumar Pati, ${ }^{2}$ Monika Anant, ${ }^{3}$ Lokesh Kumar Tiwari ${ }^{1}$
}

To cite: Prasad A, N Y, Kumar $\mathrm{P}$, et al. Excretion of SARS-CoV-2 in breast milk: a single-centre observational study. BMJ Paediatrics Open 2021;5:e001087. doi:10.1136/ bmjpo-2021-001087

Received 16 March 2021 Accepted 19 May 2021
Check for updates

\section{(c) Author(s) (or their} employer(s)) 2021. Re-use permitted under CC BY-NC. No commercial re-use. See rights and permissions. Published by BMJ.

${ }^{1}$ Department of Pediatrics, All India Institute of Medical Sciences, Patna, Bihar, India ${ }^{2}$ Department of Microbiology, All India Institute of Medical Sciences, Patna, Bihar, India ${ }^{3}$ Department of Obstetrics and Gynaecology, All India Institute of Medical Sciences, Patna, Bihar, India

Correspondence to Dr Arun Prasad; drarunp@ aiimspatna.org

\section{ABSTRACT}

Background Breast feeding by SARS-CoV-2-infected mothers has been a concern because of the possibility of excretion of virus in breast milk.

Objective To detect SARS-CoV-2 in expressed breast milk (EBM) of mothers infected with SARS-CoV-2 and clinical outcome of neonates delivered and breast fed by them.

Design A single-centre, prospective observational study involving 50 SARS-CoV-2-infected mothers and their 51 neonates.

Setting A tertiary care hospital in Eastern India.

Participants SARS-CoV-2-infected mothers and neonates delivered by them.

Main outcome measures We investigated the presence of SARS-CoV-2 in the breast milk of mothers, who tested positive for this virus in their nasopharyngeal swab (NPS). Clinical outcome was assessed in neonates breast fed by these mothers after 1 month of the postnatal period.

Results 50 SARS-CoV-2-positive expectant mothers were enrolled for the study. One out of 51 neonates, who delivered through lower segment caesarean section at term gestation and tested SARS-CoV-2 negative, died due to severe birth asphyxia. One sample of EBM was collected from each of the 49 mothers within 4 days of delivery. All EBM samples tested negative for SARS-CoV-2 through real-time reverse transcriptase-PCR (RT-PCR). All the newborns were screened twice for presence of SARSCoV-2 RNA in their NPS, by RT-PCR. 2 of 51 neonates had COVID-19 infection after 24 hours of life. Caregivers of 37 of 50 alive neonates responded to follow-up via telephone. Except for minor feed intolerance in one (1 of 37) neonate, all neonates were reported well after 1 month of their age. Conclusion All the samples of breast milk were negative for SARS-CoV-2. Most of the neonates remained asymptomatic on breast feeding, whose mothers had SARS-CoV-2 infection before delivery.

\section{INTRODUCTION}

The new coronavirus disease (COVID-19) has rapidly spread around the world since its first identification in Wuhan (China) and it was declared as pandemic by the WHO. ${ }^{1}{ }^{2}$ COVID-19 is caused by a coronavirus named SARS-CoV-2, which is associated with previously detected diseases such as severe acute respiratory syndrome, Middle East respiratory syndrome and the common cold.
What is known about the subject?

SARS-CoV-2 is transmitted through respiratory droplets.

SARS-CoV-2 is rarely excreted in breast milk.

\section{What this study adds?}

Further evidence that SARS-CoV-2 is unlikely to be excreted in breast milk.

- No significant illness was observed in infants who were breastfed for 1 month, by their mothers, who acquired SARS-CoV-2 infection before delivery.

Breast feeding is the cornerstone of infant and young child's survival, nutrition, development and maternal health. Transmission of SARS-CoV-2 from person to person through respiratory droplets is a well-established fact, but whether transmission occurs through breast milk is not well known. ${ }^{3}$ The WHO recommends exclusive breast feeding for the first 6 months of life, followed by continued breast feeding with appropriate complementary foods for up to 2 years and beyond. ${ }^{4}$ Amid the COVID-19 pandemic, there has been a concern about whether mothers with this infection should breast feed their infants. The WHO recommends that mothers with suspected or confirmed COVID-19 should be encouraged to initiate or to continue breast feeding. Mothers should be counselled that the benefits of breast feeding substantially outweigh the potential risks for transmission. ${ }^{5}$

The UNICEF recommends that the virus has not been found in breast milk and all mothers are advised to continue breast feeding while practising good hygiene during feeding which includes wearing a mask while feeding, washing hands with soap before and after touching the infant, and wiping and disinfecting regularly. The mothers, who get coronavirus shortly before giving birth and begin breast feeding and those who become infected while breast feeding, will produce 
immune factors (antibodies) in their milk to protect their infants and enhance the infant's immune responses. This means that continuing to breast feed is the best way to fight the virus and protect the neonate. If the mothers are too ill to breast feed, they should seek immediate medical advice. It may still be possible to express breast milk and ask a non-infected member of the family to feed the infant using a clean cup and spoon. It will be even more important to always follow hygiene measures to keep the neonate healthy and safe. ${ }^{6}$ National and regional guidelines from various 17 countries advocate for breast feeding, taking recommended precautions, if a mother gets infected in the peripartum period. ${ }^{7}$ Even though some studies have reported that SARS-CoV-2 has been detected in breast milk by reverse transcriptase-PCR (RT-PCR), the risk of viral transmission and infection to the neonates remains unclear. ${ }^{8-11}$ The detection of the IgA in breast milk after SARS-CoV-2 infection suggests the possibility of passive protection of neonates against SARS-CoV-2. ${ }^{12}$ The guidelines from the Centre for Disease and Prevention (CDC) and Royal College of Gynaecologist also favour breast feeding by SARS-CoV2-positive mothers. ${ }^{13}$ Hepatitis $\mathrm{B}$ virus, hepatitis $\mathrm{C}$ virus, cytomegalovirus, West Nile virus, human T-cell lymphotropic virus and HIV are some of the viruses known to be excreted in the breast milk of infected persons. ${ }^{14}$ Some Chinese experts suggest avoiding breast feeding in mothers with suspected or confirmed COVID-19. They advised initiating breast feeding only if the mother and her breast milk sample tested negative. ${ }^{15}$ Current recommendations, mostly in favour and few against, have come up on the basis of case reports and case series involving small numbers of patients estimating excretion of virus in breast milk, but a large group study is lacking. We have conducted a prospective observational study to look for the excretion of virus in the breast milk of mothers infected with SARS-CoV-2, who came for delivery in our institute. We also assessed the health condition of infants after 1 month of their age, who were breast fed by mothers detected with SARS-CoV-2 infection before delivery. Such a large group study will be helpful in further strengthening the policy of breast feeding by mothers infected with SARS-CoV-2.

\section{METHODS}

\section{Study participants}

This study involved expectant mothers with SARS-CoV-2 infection coming for delivery and their delivered neonates (figure 1).

\section{Study settings}

This study was conducted at All India Institute of Medical Sciences (AIIMS), Patna, a tertiary care medical college hospital in Eastern India which was functioning as 'dedicated COVID-19 hospital' during the pandemic of SARS-CoV-2.

\section{Study design}

This was a prospective observational study to detect presence of SARS-CoV-2 in breast milk by RT-PCR and clinical outcome of neonates delivered and breast fed by these mothers with SARS-CoV-2 infection. Informed consent for participation in the study was taken from expectant mothers, coming for delivery who were positive for the presence of viral RNA in their nasopharyngeal swab (NPS) by RT-PCR, within 10 preceding days of delivery and at the time of hospital admission. As per protocol of our institute, two samples of NPS of neonates, delivered by these mothers, were investigated for the detection of SARS-CoV-2: one within 24 hours of delivery and another after 24 hours of delivery. A single sample of expressed breast milk (EBM) was collected from each of these mothers within 4 days of delivery. Symptoms of mothers were recorded, and neonates delivered by them were monitored for development of any symptom. Neonates were kept in a designated newborn nursery of the institute until their NPS samples were investigated for the presence of SARS-CoV-2 and became fit for discharge to home. During their hospital stay, neonates were fed with their mother's EBM, once they became fit to accept feeds. Mothers were discharged as per institutional protocol. Discharge criteria for symptomatic mothers were: (a) 10 days from onset of symptoms, (b) no fever for 3 days, (c) no breathlessness/resolution of breathlessness and (d) oxygen saturation $\geq 95 \%$ without supplemental oxygen for 3 days. Symptomatic mothers were advised to be isolated at home for the next 7 days after discharge. Asymptomatic mothers were discharged home with our usual obstetrics policy of discharge after delivery, with advice to wear mask for 14 days from the day they were first detected to be RT-PCR positive for presence of viral RNA in their NPS. Neonates were discharged home with the advice of: (a) breast feeding; (b) mother to maintain hand hygiene and use of face masks while breast feeding and (c) infant's cot should be at least 1.5-2 $\mathrm{m}$ away from mother's bed during the isolation period. The discharged neonates were followed up via telephone after 1 month of their life.

\section{Questionnaire for the study}

The questionnaire for the study was prepared by a team consisting of one paediatric consultant, one paediatric resident and one neonatologist of AIIMS, Patna. The questionnaire contained questions regarding clinicodemographic information of mother and neonate. It also contained questions about the development of any symptom after discharge. Information about the frequency of micturition was included to indirectly assess the adequacy of feeding.

\section{EBM collection}

EBM samples collected manually in clean and sterile containers within 4 days of delivery were transported in viral transport media to the microbiology laboratory 
of our institute for the detection of viral RNA through RT-PCR. Samples were directly stored at $-20^{\circ} \mathrm{C}$.

\section{RNA isolation}

RNA was isolated from breast milk using the Qiagen Viral RNA Mini Kit (Qiagen, \#52906) according to the manufacturer's instructions. The $280 \mu \mathrm{L}$ samples were mixed with $1120 \mu \mathrm{L}$ lysis buffer (AVL) and incubated for $20 \mathrm{~min}$ at room temperature to ensure lysis. Then, $5.6 \mu \mathrm{g}$ carrier RNA added to each sample, followed by vortexing and an additional $10 \mathrm{~min}$ incubation at room temperature. Ethanol $(1120 \mu \mathrm{L})$ was added to it, vortexed and briefly centrifuged to remove droplets from the lid. The entire volume of lysate was then stepwise loaded onto columns. All subsequent steps were performed as instructed by the manufacturer. Viral RNA was eluted in $60 \mu \mathrm{L}$ AVE buffer. The eluted RNA was stored at $-80^{\circ} \mathrm{C}$.

\section{Qualitative RT-PCR}

Qualitative real-time RT-PCR was performed by using one-step real-time PCR reaction mixture and primerprobe mixture approved by the Indian Council of Medical Research, Government of India. Different kits were used during the period of the study depending on the availability because of the huge turnover during the pandemic. However, all of the real-time PCR kits used were capable to amplify at least one screening and one confirmatory gene. In addition, primer-probe detecting an internal control gene (human RNase P) was also included in all samples. All the patients' samples were run along with positive control and a no template control for validation of the run. Real-time RT-PCR was performed in either Biorad CFX96 or ABI Quant studio 5 Dx machine with reaction protocol set as per instruction in the kit insert.

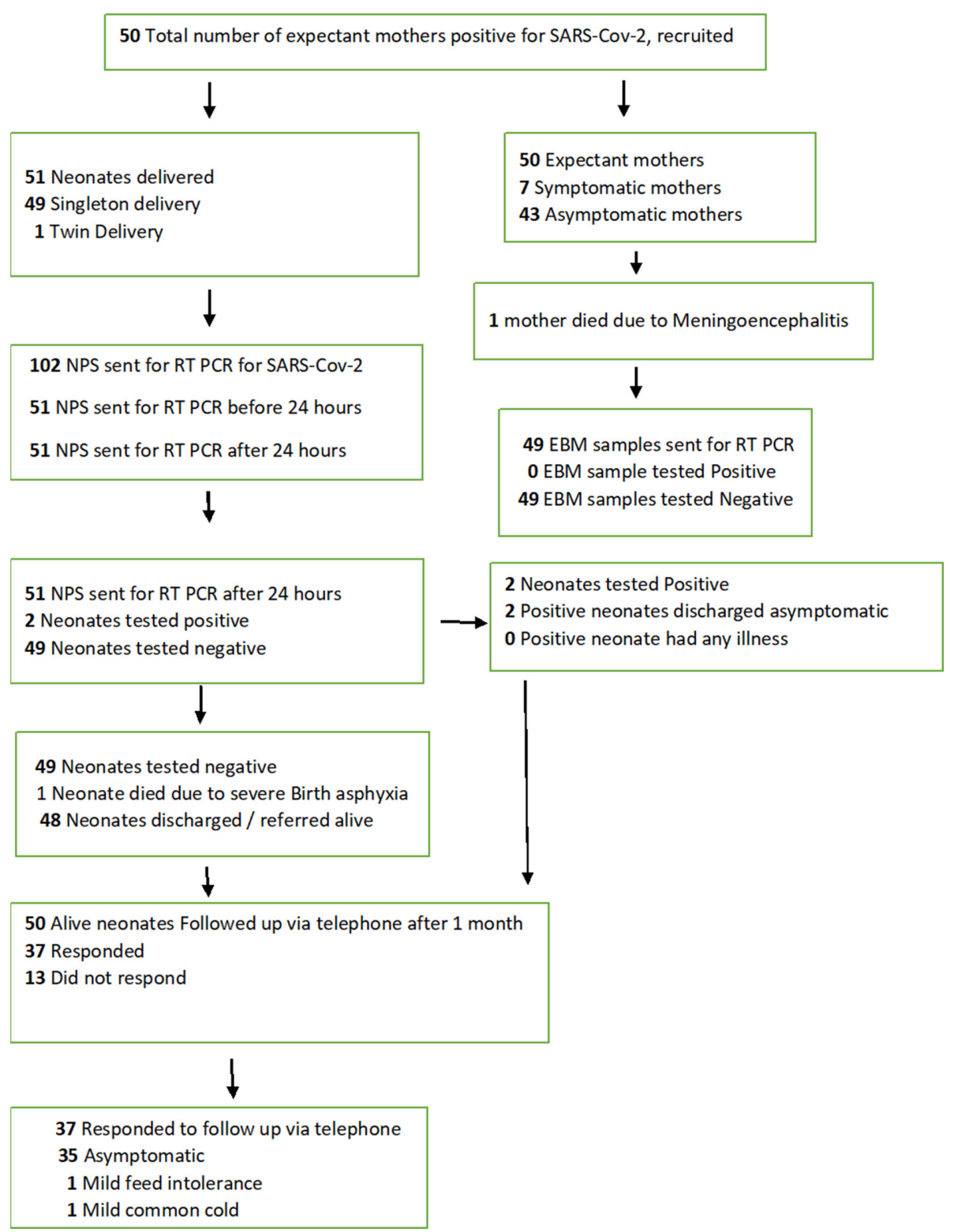

Figure 1 Flow chart of study. EBM, expressed breast milk; NPS, nasopharyngeal swab; RT-PCR, reverse transcriptase-PCR. 


\section{Patient and public involvement}

Patients or members of the public were not involved in the design or conduct of the study.

\section{RESULTS}

We included 50 COVID-19-positive mothers and 51 neonates (49 singletons and 1 twin delivery). Out of 50 deliveries, 9 were preterm and 41 were term deliveries. Ten of $50(20 \%)$ mothers delivered through normal vaginal delivery (NVD), and 40 of $50(80 \%)$ mothers delivered through lower segment caesarean section (LSCS). Seven out of 50 mothers were symptomatic due to COVID-19 infection (figure 2). One out of these 50 mothers (2\%) died after 4 days of delivery, due to meningoencephalitis associated with COVID-19 after delivering through NVD, whose infant was asymptomatic and COVID-19 negative. One out of 51 neonates $(1.96 \%)$, who was delivered at full term through LSCS, tested COVID-19 negative, died after 48 hours of life, due to severe birth asphyxia secondary to meconium aspiration syndrome. Another neonate with severe birth asphyxia left against medical advice. All the samples of EBM collected from 49 mothers within 4 days of delivery were tested negative for SARS-CoV-2. Two of $51(3.92 \%)$ neonates had RT-PCR-confirmed SARS-CoV-2 infection postnatally after 24 hours of life during which they were fed with formula feed; both were delivered through caesarean section. Hence, breast feeding is an unlikely mode of infection in them. Both of COVID-19-positive neonates were asymptomatic. Forty-three out of 51 neonates $(84.3 \%)$ of COVID-19-positive mothers were asymptomatic after their birth. Overall, 8 of $51(16 \%)$ neonates were symptomatic. In our study, birth asphyxia was the most common symptom $(4,8 \%)$ followed by neonatal hyperbilirubinaemia $(2,4 \%)$, abdominal distension due to mesenteric cyst $(1,2 \%)$ and transient feed intolerance $(1,2 \%)$ which could not be attributed to COVID-19. The neonates were followed up via telephone after 1 month of age. Neonatal growth and adequacy of breast feeding in the postnatal period were indirectly monitored in terms of frequency of micturition per day. They were also asked

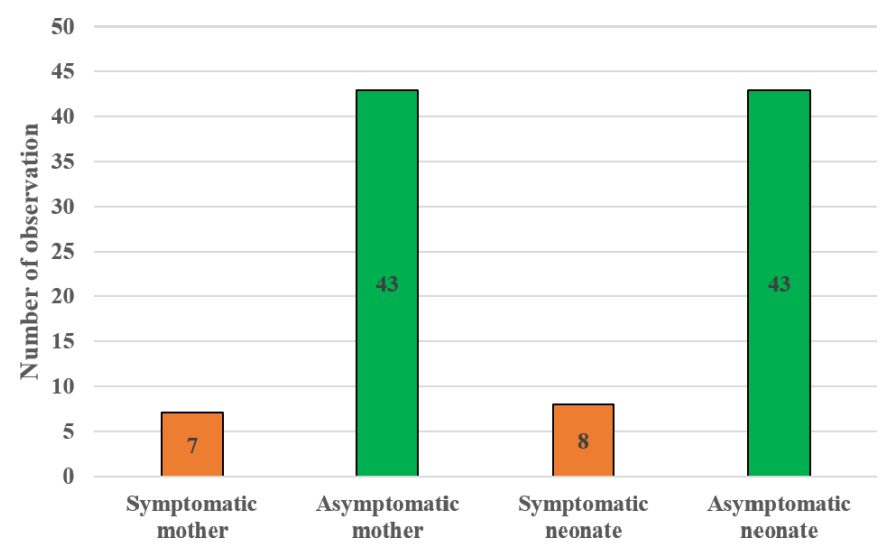

Figure 2 Clinical status of mothers and neonates during hospital admission. about any health issues noticed during their postnatal life after discharge from the hospital. Caregivers of 37 of 50 discharged neonates $(74 \%)$ responded to follow-up via telephone and all were having adequate breast feeding and passing adequate urine ( $\geq 7$ times per day). Among 37 neonates, who responded to follow-up, 35 infants were asymptomatic, 1 had minor feed intolerance and another had common cold.

\section{DISCUSSION}

Delivery of neonates by SARS-CoV-2-positive mothers is a special situation, where vertical transmission to the neonate, excretion of virus in breast milk and the possibility of infection to the neonates have been concerns. Most studies on this topic have been on North American populations and that similar data from more diverse populations, including India, have been lacking. Moreno et $a l$, in their study involving 19 mothers infected with SARS-CoV-2, have not found vertical transmission to any neonate. ${ }^{16}$ Kotlyar et al, in a meta-analysis, have found that vertical transmission of SARS-CoV-2 seems to occur in a minority (3.2\%) of cases of maternal COVID-19 infection in the third trimester. ${ }^{17}$ Islam et aldid not find any evidence of vertical transmission from mother to her fetus. ${ }^{18}$ The findings of our study support the WHO, UNICEF and CDC policy of advocating breast feeding by SARS-CoV-2infected mothers. Our findings resemble a meta-analysis conducted by Islam et al. ${ }^{18}$ Chambers et al detected 1 of 18 samples of breast milk positive for SARS-CoV-2 by RT-PCR. ${ }^{19}$ Martins-Filho analysed the presence of SARS-CoV-2 in the breast milk of pregnant woman with COVID-19 during the third trimester of pregnancy. All patients in that study had a fever or respiratory symptoms and no breast milk sample was positive for SARS-CoV-2. ${ }^{20}$ In our study, $80 \%$ of mothers have delivered through LSCS as compared with $20 \%$ delivered through the vaginal route. This was in contrast $(79 \%$ vaginal and $21 \%$ caesarean) to a study conducted by Harrison et al involving pregnant women without COVID-19 in India. ${ }^{21}$ Eighty-two per cent of women enrolled in our study delivered at term, compared with $87 \%$ of women delivering at term in a study conducted in low-income and middleincome countries. Two per cent of deliveries in our study were complicated by neonatal mortality (died due to birth asphyxia), which is also comparable with neonatal mortality rate $(2 \%)$ in the study by Harrison $e t a l .^{21}$ These data suggest that birth outcome, in terms of preterm deliveries and neonatal mortality in SARS-CoV-2-infected mothers, is not significantly different as compared with those in non-infected mothers. Various other authors have also reported neonatal mortality ranging from $0.6 \%$ to $2 \%$ as an outcome of pregnancy in SARS-CoV2-infected mothers. In our study, 2 of 51 neonates tested SARS-CoV-2 positive, 24 hours after delivery. Both were fed on formula milk during the initial period of life due to inadequate volume of EBM. Hence, breast feeding cannot be associated with their SARS-CoV-2 positivity in 
two neonates, who had tested positive in our study. They have got the infection most likely from the environment. Both these neonates were discharged in asymptomatic condition. The findings of our study support advocating the policy of breast feeding by SARS-CoV-2-positive mothers, following recommended ${ }^{22}$ precautions during isolation like: (1) washing hands using soap and water before expressing breast milk either by hand expression or with a breast pump (if soap and water are not available, use hand sanitiser with at least $60 \%$ alcohol); (2) wearing a mask when expressing breast milk either by hand expression or with a breast pump; and (3) infant's cot should be at least 1.5-2 $\mathrm{m}$ away from mother's bed. We recommend exclusive breast feeding by mothers, directly through their breast thereafter for 6 months of infants' age, wearing a mask for 1 more week, maintaining hand hygiene and breast hygiene.

Acknowledgements We are thankful to the mothers who have participated in this study.

Contributors LKT was involved in planning this research. AP, YN and PK were involved in collecting data. BKP was involved in investigating the presence of SARS-CoV-2 in breast milk. MA and BKC were involved in care of mothers and neonates, respectively. All authors approved the final draft of the manuscript.

Funding The authors have not declared a specific grant for this research from any funding agency in the public, commercial or not-for-profit sectors.

Competing interests None declared.

Patient and public involvement Patients and/or the public were not involved in the design, or conduct, or reporting, or dissemination plans of this research.

Patient consent for publication Not required.

Ethics approval This study was reviewed and approved by the Institute Ethics Committee of All India Institute of Medical Sciences, Patna.

Provenance and peer review Not commissioned; externally peer reviewed.

Data availability statement Data are available upon reasonable request. All data relevant to the study are included in the article or uploaded as supplemental information. Data are available on reasonable request. All relevant data are available on reasonable request by emailing the corresponding author.

Open access This is an open access article distributed in accordance with the Creative Commons Attribution Non Commercial (CC BY-NC 4.0) license, which permits others to distribute, remix, adapt, build upon this work noncommercially, and license their derivative works on different terms, provided the original work is properly cited, appropriate credit is given, any changes made indicated, and the use is non-commercial. See: http://creativecommons.org/ licenses/by-nc/4.0/.

ORCID iD

Arun Prasad http://orcid.org/0000-0002-7532-948X

\section{REFERENCES}

1 Dhama K, Khan S, Tiwari R, et al. 2019-COVID-19. Clin Microbiol Rev 2020;33:e00028-20.

2 Cucinotta D, Vanelli M. Who Declares COVID-19 a pandemic. Acta Biomed 2020;91:157-60.

3 Meselson M. Droplets and aerosols in the transmission of SARSCoV-2. N Engl J Med 2020;382:2063.

4 World Health Organization. Global nutrition targets 2025: breastfeeding policy brief [Accessed 1 Mar 2021].

5 World Health Organization. Clinical management of COVID-19: interim guidance (27 may 2020. Geneva, Switzerland: World Health Organization, 2020.

6 Breastfeeding during the COVID-19 pandemic. Available: https:// www.unicef.org/eap/breastfeeding-during-covid-19 [Accessed 21 Aug 2020]

7 Yeo KT, Oei JL, De Luca D, et al. Review of guidelines and recommendations from 17 countries highlights the challenges that clinicians face caring for neonates born to mothers with COVID-19. Acta Paediatr 2020;109:2192-207.

8 Kirtsman M, Diambomba Y, Poutanen SM, et al. Probable congenital SARS-CoV-2 infection in a neonate born to a woman with active SARS-CoV-2 infection. CMAJ 2020;192:E647-50.

9 YLC W, Dong L, Zhang C. Viral shedding of COVID-19 in pregnant women SSRN 2020

10 Buonsenso D, Costa S, Sanguinetti M, et al. Neonatal late onset infection with severe acute respiratory syndrome coronavirus 2. Am $J$ Perinatol 2020;37:869-72.

11 Groß R, Conzelmann C, Müller JA, et al. Detection of SARS-CoV-2 in human breastmilk. Lancet 2020;395:1757-8.

12 AMJ F, Amanat F, Krammer F. Evidence of a significant secretoryIgA-dominant SARSCoV- 2 immune response in human milk following recovery from COVID-19. medRxiv.

13 Evaluation and Management Considerations for Neonates At Risk for COVID-19. Available: https://www.cdc.gov/coronavirus/2019-ncov/ hcp/caring-for-newborns.html [Accessed 21 Nov 2020].

14 Lawrence RM, Lawrence RA. Breast milk and infection. Clin Perinato 2004;31:501-28.

15 Bhatt H. Should COVID-19 mother breastfeed her newborn child? A literature review on the safety of breastfeeding for pregnant women with COVID-19. Curr Nutr Rep 2021;10:71-5.

16 Moreno SC, To J, Chun H, et al. Vertical transmission of COVID-19 to the neonate. Infect Dis Obstet Gynecol 2020;2020:1-5.

17 Kotlyar AM, Grechukhina O, Chen A, et al. Vertical transmission of coronavirus disease 2019: a systematic review and meta-analysis. Am J Obstet Gynecol 2021;224:35-53.

18 Islam MM, Poly TN, Walther BA, et al. Clinical characteristics and neonatal outcomes of pregnant patients with COVID-19: a systematic review. Front Med 2020;7:573468.

19 Chambers C, Krogstad P, Bertrand K, et al. Evaluation for SARS-CoV-2 in breast milk from 18 infected women. JAMA 2020;324:1347-8.

20 Martins-Filho PR. To breastfeed or not to breastfeed? lack of evidence on the presence of SARS-CoV-2 in breastmilk of pregnant women with COVID-19. Rev Panam Salud Publica 2020.

21 Harrison MS, Pasha O, Saleem S, et al. A prospective study of maternal, fetal and neonatal outcomes in the setting of cesarean section in low- and middle-income countries. Acta Obstet Gynecol Scand 2017:96:410-20.

22 Care for Breastfeeding People. Interim guidance on breastfeeding and breast milk feeds in the context of COVID-19. Available: https:// www.cdc.gov/coronavirus/2019-ncov/hcp/care-for-breastfeedingwomen.html [Accessed 12 May 2021]. 